Saudi Journal of Oral and Dental Research

Abbreviated Key Title: Saudi J Oral Dent Res

ISSN 2518-1300 (Print) |ISSN 2518-1297 (Online)

Scholars Middle East Publishers, Dubai, United Arab Emirates

Journal homepage: https://saudijournals.com

\title{
Comparison of Knowledge and Perception of Orthodontic Treatment among Dental Students and Local Population
}

\author{
Muhammad Ilyas ${ }^{1}$, Asmi Shaheen ${ }^{2}$, Salsabeel Amjad ${ }^{3}$, Tayyeba Zubair ${ }^{4}$, Amina Tariq ${ }^{5 *}$ \\ ${ }^{1}$ FCPS, Associate Professor Orthodontist, de 'Montmorency College of Dentistry, Lahore, Pakistan \\ ${ }^{2}$ Assistant Professor Orthodontist, de 'Montmorency College of Dentistry, Lahore, Pakistan \\ ${ }^{3} \mathrm{BDS}$, de 'Montmorency college of Dentistry, Lahore Pakistan \\ ${ }^{4}$ PGR Orthodontist, de 'Montmorency College of Dentistry, Lahore, Pakistan \\ ${ }^{5}$ Postgraduate Research Coordinator, University College of Medicine and Dentistry, University of the Lahore, Pakistan
}

DOI: $10.36348 /$ sjodr.2021.v06i01.012

| Received: 29.12.2020 | Accepted: 11.01.2021 | Published: 16.01.2021

*Corresponding author: Amina Tariq

\section{Abstract}

People's perception, awareness and knowledge about their occlusion and esthetics has great impact on their attitude towards orthodontic treatment. In order to assess and compare the knowledge and self-awareness of orthodontic problem and treatment need between dental student and local population a survey was conducted As Patient's self-perception is of significant importance in successful orthodontic treatment planning. The participants included 110 adults including local population and dental students of Punjab and almost most of them were 20-30 years old. The participants' opinion regarding self-awareness and orthodontic treatment need was recorded on a specifically designed questionnaire. $61.7 \%$ people were aware of their occlusion and most of them were dental studens.38.3\% people are afraid of orthodontic treatment due to lack of knowledge and awareness. Dental students had awareness and good knowledge, thus positive attitude towards orthodontics. Local population had little or no knowledge about orthodontic treatment need and most lay people had negative attitude towards orthodontic treatment.

Keywords: Self-awareness, orthodontic treatment, malocclusion, People's perception, Dental esthetics.

Copyright (C) 2021 The Author(s): This is an open-access article distributed under the terms of the Creative Commons Attribution 4.0 International License (CC BY-NC 4.0) which permits unrestricted use, distribution, and reproduction in any medium for non-commercial use provided the original author and source are credited.

\section{INTRODUCTION}

To evaluate and record the perception of malocclusion and its treatment need in a population is valuable and extremely handy for planning of orthodontic treatment. Without a satisfactory estimate of the need and demand for treatment it is challenging to plan and organize promising and valuable orthodontic treatment.

Malocclusion is a common problem which affects the physical, social, psychological and sometimes economical well-being. They can also affect the quality of life including function, appearance and self-confidence. Oral health related quality of life relates to the impact of dental esthetics on social acceptance and self-acceptance [1]. Malocclusion may cause patient to develop low self-esteem as their facial appearance is affected and thus, they feel embarrassed in social environment. Some people are contented even with severe malocclusion while others can be meticulous about minor irregularities and many of them are actually not concerned of their occlusion.
Psychosocial issues have been the main concerns for most of people demanding orthodontic treatment [2-6]. Relationship between self-perception of malocclusion and actual clinical status has been investigated by many researchers and they can generally conclude that self-awareness and clinical statues are not strongly correlated [7-9].

Gender, Age, Self-esteem, and education have been suggested as factors affecting the self-perception of dental appearance, malocclusion and attitude towards orthodontic treatment. Decision to provide and accept orthodontic treatment are not defined only by orthodontist, but patient's perception of self-esteem and self-concept is more important contributing factor. Patient's perception of malocclusion can't be underestimated as Patient's self-perception is of significant importance in determining treatment demand and co-operation [10].

The rate of starting orthodontic treatment and its outcome can be decided not only by severity of malocclusion but other background factors such as age, gender, education, a socioeconomic status play an

Citation: Muhammad Ilyas et al (2021). Comparison of Knowledge and Perception of Orthodontic Treatment among Dental Students 59 and Local Population. Saudi J Oral Dent Res, 6(1): 59-62. 
important role[11]. Pain due to orthodontic treatment is of considerable important to patients who is generally overlooked by the dentists and this factor negatively affects patient's willingness, compliance, cooperation. Due to this reason most of the people intentionally delay orthodontic treatment.

Therefore, the purpose of this survey was to investigate and compare self-perception and satisfaction of dentofacial appearance among dental students and local population. The objectives of this survey were to assess the knowledge about self-awareness and attitude towards orthodontic treatment and to compare them between dental students and local population.

\section{MATERIAL AND METHOD}

The questionnaire-based survey was used to collect the data about the knowledge and perception of people. The participants of this survey were divided broadly in two groups 1- Dental students 2- local population. Total number of participants was 110 and almost half of them were dental students and half were local people.

The questionnaire was specially designed in order to assess the perception, knowledge, subject's ability to recognize the presence and absence of malocclusion, knowledge to perceive the effect of malocclusion on one's life and their attitude towards orthodontic treatment and comparison of perception between the two main groups used.

\section{RESULTS}

Total of 109 participants agreed to fill the questionnaire to complete the survey. $50 \%$ of dental students and $50 \%$ were of local population

95.3\% were between $20-30$ Years old, $79.4 \%$ were females and $20.6 \%$ were males, $61.7 \%$ were well aware of their occlusion $15.9 \%$ didn't know about their occlusion and $22.4 \%$ were confused, $87 \%$ didn't have any problem with their occlusion.

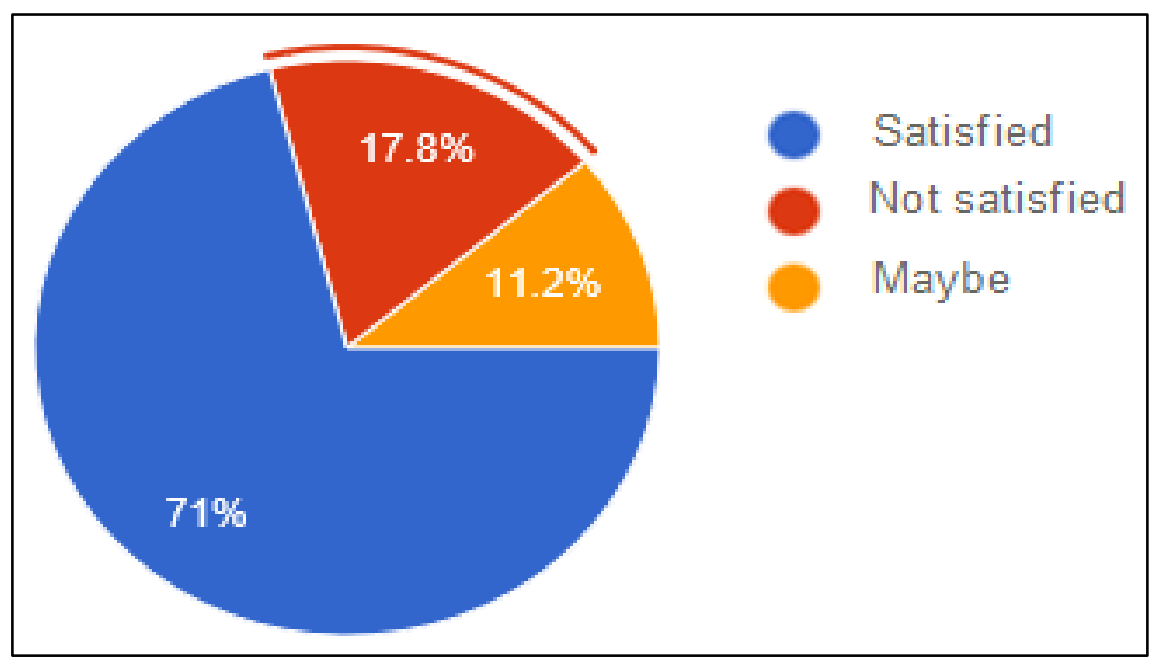

People's satisfaction about their dental appearance

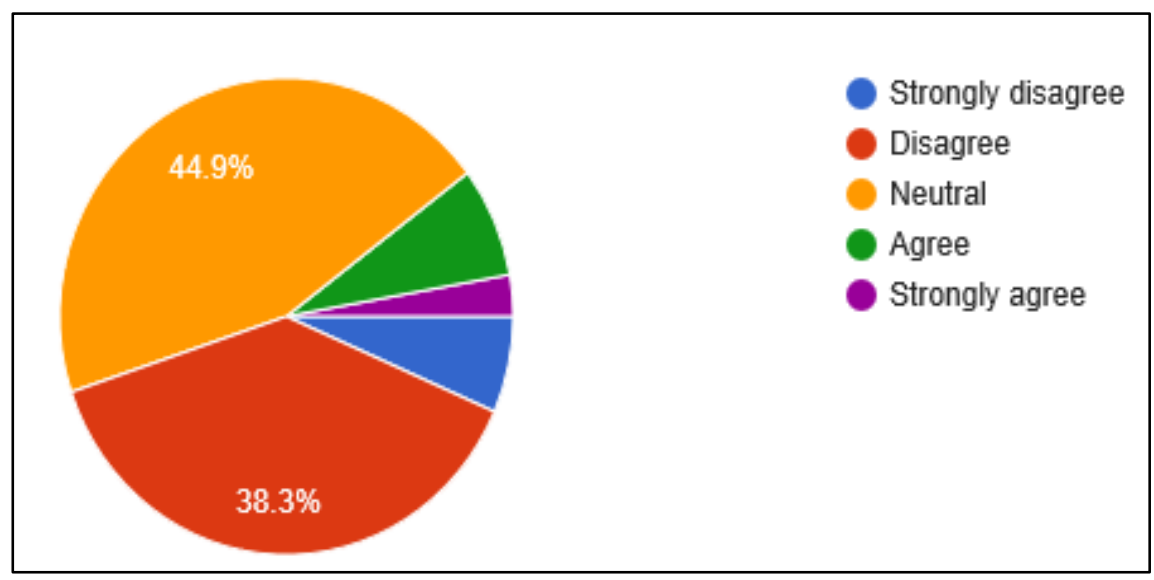

People's view on if extraction is always necessary for orthodontic treatment 


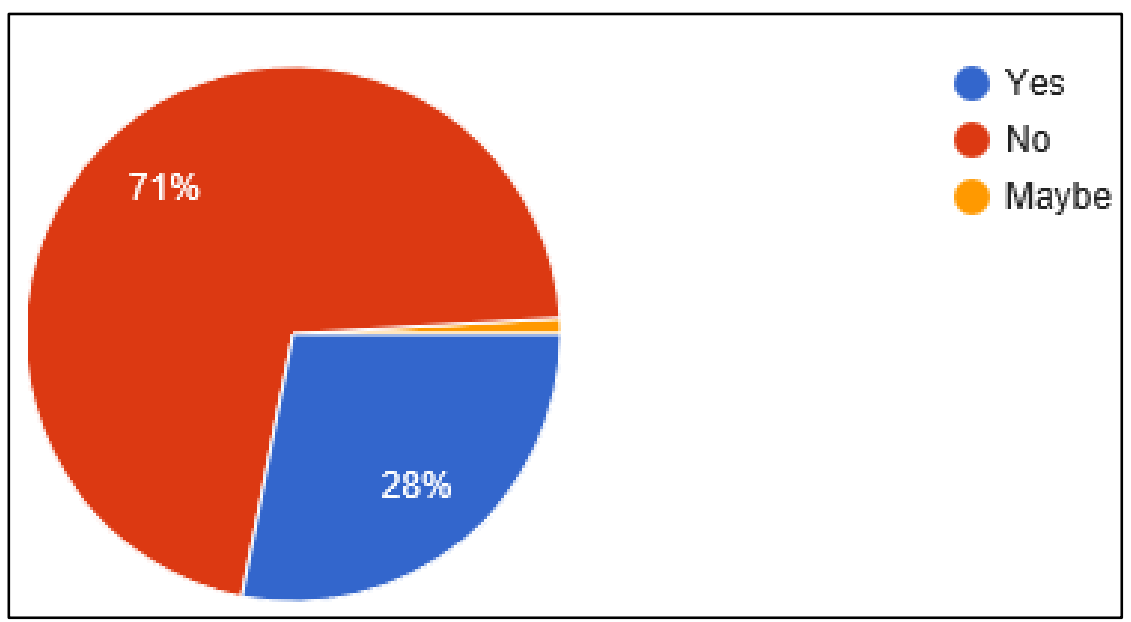

People who have undergone orthodontic treatment

Perception of people about effect of occlusion on their lives is reported by $57.9 \%$ as occlusion does not affect overall health status. $26.2 \%$ think it does and $15.9 \%$ were unsure. $68.2 \%$ think that malocclusion has bad psychosocial affect $14 \%$ were against this opinion and $17.8 \%$ people were unsure about that. $86.9 \%$ people have opinion that normal occlusion is very important for good facial profile hence more confidence $7.5 \%$ was against this opinion and $5.6 \%$ had no idea about that.

$28 \%$ included in the survey had undergone orthodontic treatment and $78.5 \%$ were willing to seek orthodontic treatment if their dentist recommends them

Table-1: Perception towards orthodontics treatment

\begin{tabular}{|l|l|l|l|}
\hline Statements & YES & NO & MAYBE \\
\hline Are you afraid of orthodontic treatment? & $38.3 \%$ & $48.6 \%$ & $13.1 \%$ \\
\hline Have you ever thought of seeking orthodontic treatment just for esthetics? & $50.5 \%$ & $41.1 \%$ & $8.4 \%$ \\
\hline Will you seek orthodontic treatment if your orthodontist recommends it for you? & $78.5 \%$ & $8.4 \%$ & $13.1 \%$ \\
\hline Do you think orthodontic treatment is very lengthy and painful procedure? & $59.4 \%$ & $11.3 \%$ & $29.2 \%$ \\
\hline Do you think orthodontic treatment gives promising result? & $12.1 \%$ & $24.3 \%$ & $60.7 \%$ \\
\hline
\end{tabular}

\section{DISCUSSION}

The self-awareness and knowledge of patient about orthodontic treatment is of great importance and can't be underestimated for successful treatment planning and promising results as it is the patients who receive treatment and need to gain satisfaction [12].

With modern life style cases of malocclusion has increased mainly due to soft diet and many other factors. Many people overlook their malocclusion as they don't think it has significant effect on their lives and many people don't seek orthodontic treatment because of fear of pain, long duration of treatment and expenditure. When questions regarding their occlusions were asked it was concluded that most of the people had no idea about their occlusion and most of the people mainly lay people were of view that malocclusion is nothing to do with overall health status. Most of lay people have negative attitude towards orthodontic treatment due to fear of pain which is associated with orthodontic treatment and also due to lack of knowledge. In developing countries, malocclusion is still overlooked because priorities are given to dental caries and periodontal problems because of association of pain with them [13].
As people grow and interact with different environment their ideas of self-concepts are developed according to different areas of their lives. Self-concept is generally thought to represent a learned, organized response pattern [14] that is influenced by reactions of other people, their own positive and negative experiences and one's ability to grow to achieve his goals [15].

Dental students who have more knowledge of orthodontic treatment are aware of dental esthetics, while most of people from local population give no importance to dental esthetics due to lack of awareness.

There is some evidence that local population fails to accurately describe their occlusal characteristics and almost have no or very little knowledge about orthodontic treatment. Difference not only exist in perception of orthodontic treatment need between dental students and local population but certain variations also exist among dental students themselves. These differences are basically due to different level of awareness and knowledge. 
Muhammad Ilyas et al; Saudi J Oral Dent Res, Jan, 2021; 6(1): 59-62

Poor facial profile due to malocclusion is the major motivating factors for considering orthodontic treatment while other aspects are usually ignored and patients usually avoid orthodontic treatment is their facial profile is not affected.

Orthodontic treatment need is mainly broken in several steps such as patient awareness, selfsatisfaction, and attitude towards orthodontic treatment. We may postulate that dental students have good knowledge about dental esthetics and other malocclusion related problems. Lack of knowledge is main factor keeping the patients away from seeking orthodontic treatment.

\section{CONCLUSION}

The questionnaire assessed the knowledge about self-awareness and attitude of people towards orthodontic treatment. Dental students had better knowledge and self-awareness and positive attitude towards orthodontic treatment while local population lack the knowledge and awareness and mostly were afraid of the treatment.

\section{REFERENCES}

1. Ashky, R. T., Althagafi, N. M., Alsaati, B. H., Alharbi, R. A., Kassim, S. A., \& Alsharif, A. T. (2019). Self-Perception Of Malocclusion And Barriers To Orthodontic Care: A Cross-Sectional Study In Al-Madinah, Saudi Arabia. Patient preference and adherence, 13, 1723.

2. Shaw, W. C., Addy, M., \& Ray, C. (1980). Dental and social effects of malocclusion and effectiveness of orthodontic treatment: a review. Community Dentistry and Oral Epidemiology, 8(1), 36-45.

3. Stricker, G. (1970). Psychological issues pertaining to malocclusion. American Journal of Orthodontics and Dentofacial Orthopedics, 58(3), 276-283.

4. Secord, P. F., \& Backman, C. W. (1959). Malocclusion and psychological factors. The Journal of the American Dental Association, 59(5), 931-938.
5. Albino, J. E., Cunat, J. J., Fox, R. N., Lewis, E. A., Slakter, M. J., \& Tedesco, L. A. (1981). Variables discriminating individuals who seek orthodontic treatment. Journal of Dental Research, 60(9), 16611667.

6. Kenealy, P., Frude, N., \& Shaw, W. (1989). An evaluation of the psychological and social effects of malocclusion: some implications for dental policy making. Social Science \& Medicine, 28(6), 583-591.

7. Espeland, L. V., Ivarsson, K., Stenvik, A., \& Alstad, T. A. (1992). Perception of malocclusion in 11-year-old children: a comparison between personal and parental awareness. The European Journal of Orthodontics, 14(5), 350-358.

8. Lindsay, S. J. E., \& Hodgkins, J. F. W. (1983). Children's perceptions of their own malocclusions. British Journal of Orthodontics, 10(1), 13-20.

9. Espeland, L. V., \& Stenvik, A. (1991). Perception of personal dental appearance in young adults: relationship between occlusion, awareness, and satisfaction. American Journal of Orthodontics and Dentofacial Orthopedics, 100(3), 234-241.

10. Spalj, S., Slaj, M., Varga, S., Strujic, M., \& Slaj, M. (2010). Perception of orthodontic treatment need in children and adolescents. The European Journal of Orthodontics, 32(4), 387-394.

11. Kim, Y. (2017). Study on the perception of orthodontic treatment according to age: A questionnaire survey. The Korean Journal of Orthodontics, 47(4), 215-221.

12. Agrawal, R. (2018). Knowledge, attitude and perception of orthodontic treatment among dental students. Int J Dent Res, 6(1), 3-5.

13. Dr. Roopa, S., Dr. Rani. M.S. (2013). Open Journal of Dentistry and Oral Medicine, 1(1): 5-8,

14. Grain, R. M., \& Bracken, B. A. (1994). Age, race, and gender differences in child and adolescent selfconcept: Evidence from a behavioral-acquisition, context-dependent model. School Psychology Review, 23(3), 496-511.

15. Braken, B. A. (1992). Multidimensional Self Concept Scale: Examiner's Manual. Texas: Pro-ed. 